\title{
AVIFAUNA DE QUATRO FISIONOMIAS FLORESTAIS DE PEQUENO TAMANHO (5-8 ha) NO CAMPUS DA UFLA
}

\author{
SANTOS D'ANGELO NETO, NELSON VENTURIN, \\ ARY T. DE OLIVEIRA FILHO e FERNANDO A. FRIEIRO COSTA \\ Universidade Federal de Lavras, UFLA, Departamento de Ciências Florestais, \\ Campus Universitário, CP 37, CEP 37200-200, Lavras, MG, Brasil \\ Correspondência para: Nelson Venturin, Universidade Federal de Lavras, UFLA, Departamento de Ciências \\ Florestais, Campus Universitário, CP 37, CEP 37200-000, Lavras, MG, Brasil \\ Recebido em 19/05/97 - Aceito em 02/06/98 - Distribuído em 28/08/98
}

\begin{abstract}
Survey and Characterization of the Avifauna in the Campus of the Ufla

This work was conducted in the campus of the Universidade Federal de Lavras (UFLA), at $21^{\circ} 13^{\prime} 40^{\prime \prime}$ $\mathrm{S}$ and $44^{\circ} 57^{\prime} 50^{\prime \prime} \mathrm{WG}$. The authors marked a track of about $300 \mathrm{~m}$ long within four forest fragments found in the campus and, between April and November of 1995, visited these tracks recording the number of species and individuals of as well as ecological patterns of each species, such as feeding habits and position occupied in the vegetation stratum. From the data obtained, the following abundance parameters were calculated: avifauna similarity among the sites and the index of diversity. A total of 107 bird species were recorded in the forest fragments. It was noted an absence of several families of more specialized forest birds, such as Tinamidae, Contingidae and Trogonidae and of species of the families Dendrocolaptidae, Formicariidae, Pipridae and Picidae when compared to a tract of semideciduous montane forest of the Poço Bonito Forest Reserve, representing a loss of about $48 \%$ of forest birds species, probably due to their very reduced sizes. This work demonstrates the inefficiency of very small forest fragments in maintaining certain more especialized forest bird species and the need of preserving larger fragments that are still left for conservation in the region.
\end{abstract}

Key words: birds, fragmentation, species loss.

\section{RESUMO}

Este trabalho foi realizado na área do campus da Universidade Federal de Lavras (UFLA), nas coordenadas de $21^{\circ} 13^{\prime} 40^{\prime \prime}$ sul e $44^{\circ} 57^{\prime} 50^{\prime}$ " oeste. Foi marcada uma trilha de cerca de $300 \mathrm{~m}$ de extensão em quatro fisionomias florestais encontradas no campus e, entre abril e novembro de 1995, foram visitados mensalmente estes locais, registrando o número de espécies e indivíduos ao longo da trilha, e também observados os padrões ecológicos de cada espécie, como forrageamento e estrato de mata ocupado. Com os dados coletados no levantamento quantitativo, foram calculados alguns parâmetros de abundância para cada local, a similaridade avifaunística entre eles e o índice de diversidade. Como resultado, foram registradas 107 espécies de aves nas quatro fisionomias florestais do campus. Notouse nestas fisionomias a ausência de várias famílias de aves florestais mais especializadas, como Tinamidae, Cotingidae e Trogonidae, e espécies das famílias Dendrocolaptidae, Formicariidae, Pipridae e Picidae, quando comparadas a uma mancha de floresta semidecídua montana da Reserva Florestal do Poço Bonito. Houve uma perda de cerca de $48 \%$ das aves florestais nos fragmentos encontrados no campus em relação à avifauna florestal da reserva, provavelmente devido aos seus tamanhos muito reduzidos (5 a 8 ha). Este trabalho mostra a ineficiência de fragmentos florestais muito pequenos em manter determinadas espécies de aves florestais mais especialistas e a necessidade de preservação de fragmentos maiores que ainda restem para a conservação das espécies que ainda ocorrem na região.

Palavras-chave: aves, fragmentação, perda de espécies. 


\section{INTRODUÇÃO}

A América do Sul é considerada o continente das aves. Vivem aqui cerca de um terço das espécies de aves existentes na Terra (Negret et al., 1984). No Brasil, ocorrem 1.676 espécies de aves, entre espécies residentes e visitantes, correspondendo a mais da metade das espécies de aves registradas para a América do Sul (Andrade, 1995). No entanto, o país vem sofrendo grande desmatamento no decorrer do tempo, principalmente na Região Sudeste. A cobertura florestal original do estado de Minas Gerais, por exemplo, foi reduzida a $2 \%$ do original (Sick, 1985). A redução da cobertura florestal a fragmentos muito pequenos tem trazido consequiências negativas para a avifauna, empobrecendo-a consideravelmente. Como consequiência, há uma diminuição no número de espécies mais especializadas, conservando na sua maioria apenas as generalistas.

Este trabalho tem por objetivo apresentar os resultados de levantamentos quantitativos realizados em quatro fisionomias florestais de pequeno tamanho (5-8 ha) encontradas no campus da Universidade Federal de Lavras (UFLA) e compará-los, em termos de presença-ausência de espécies, com um levantamento realizado em uma mancha de floresta estacional semidecídua montana de cerca de 72 ha localizada na Reserva Florestal do Poço Bonito.

\section{MATERIAL E MÉTODOS}

\section{Área de estudos}

A coleta de dados foi realizada em quatro locais dentro da área do campus da Universidade Federal de Lavras, situada no município de Lavras, região sul de Minas Gerais. As coordenadas geográficas do centro do campus são $21^{\circ} 13^{\prime} 40^{\prime \prime}$ de latitude sul e 44 $57^{\prime} 50^{\prime \prime}$ de longitude oeste, situando-se a uma altitude média de $900 \mathrm{~m}$. O clima do município é do tipo Cwb de Köppen (mesotérmico com verões brandos e suaves e estiagem de inverno). A precipitação e a temperatura médias anuais são de $1.493,3 \mathrm{~mm}$ e $19,3^{\circ} \mathrm{C}$, respectivamente, $66 \%$ da precipitação ocorrendo no período de novembro a fevereiro (Vilela \& Ramalho, 1979).

\section{Locais de trabalho}

a) Local 1 - Reserva Florestal da UFLA, também conhecida como "Matinha"

Localizada no final da avenida principal do campus, é um fragmento de 5,8 ha de floresta estacional semidecídua montana, segundo a classificação do IBGE (Veloso, Rangel Filho \& Lima, 1991). A topografia é plana. Ocorrem muitas clareiras por queda de árvores. O dossel é aberto e está entre 12 e $15 \mathrm{~m}$ de altura, com algumas árvores chegando a $20 \mathrm{~m}$. As espécies de árvores representativas são Copaifera langsdorfii, Xylopia brasiliensis, Sclerolobium rugosum, Ocotea corymbosa, Cryptocarya aschersoniana, Tapirira obtusa e Ocotea odorifera. O sub-bosque é denso e tem como espécies representativas Miconia hispida, Miconia pepericarpa e Calyptranthes clusiaefolia. Este local não possui fonte de água no seu interior e, dos quatro locais de trabalho, é o menos perturbado.

\section{b) Local 2 - Mata da subestação}

Localizada numa encosta voltada para o sudoeste, atrás da Estação Experimental da EPAMIG, é um fragmento de 8 ha de floresta estacional semidecídua montana. Possui um declive ligeiramente acentuado na direção de um córrego que margeia a mata. Há algumas áreas com muita densidade de cipós e clareiras com predominância de Cecropia pachystachya, bem distribuídas pela mata. O dossel é aberto e está a cerca de $15 \mathrm{~m}$ de altura, podendo variar bastante em alguns pontos, onde baixa para $10 \mathrm{~m}$, e tem como árvores representativas Miconia cinnamomifolia, Piptadenia gonoacantha, Maprounea guianensis e Cabralea canjerana. O subbosque é denso, com abundância de Rubiáceas, Rutáceas, Monimiáceas, Mirtáceas e jovens de pindaíba (Xylopia brasiliensis). Este local é bem mais perturbado que o Local 1, o que é veri-ficado pela abundância de Miconia cinnamomifolia no dossel e de Coffea arabica no sub-bosque. Em seu interior passa um pequeno córrego d'água.

\section{c) Local 3 - Mata da Capela}

Localizada atrás da Capela Ecumênica da UFLA, próximo ao pomar e margeando a represa de captação de água, a Mata da Capela possui uma área de cerca de 8 ha e apresenta uma vegetação secundária proveniente de um eucaliptal desbastado e abandonado há mais de 50 anos, tendo um subbosque bem desenvolvido. Os eucaliptos chegam a $30 \mathrm{~m}$ de altura. A regeneração, com predominância de Piptadenia gonoacantha e indivíduos dispersos de Machaerium nyctians, Luehea grandiflora e Maclura tinctoria, chega a 12-15 metros de altura. A densidade do sub-bosque é muito variável e existem poucas clareiras no local. 
A topografia é de um declive suave em direção à represa.

\section{d) Local 4 - Eucaliptal}

Localizado atrás do Viveiro Florestal da UFLA e próximo ao Local 1 e a uma mata de angico que foi estabelecida em $1956 \mathrm{com}$ a finalidade de avaliar o sombreamento do café por angico-vermelho (Anadenanthera peregrina). O Eucaliptal tem cerca de 2,9 ha e foi implantado nos anos de $1974 \mathrm{e}$ 1975 com finalidade de informar às empresas de reflorestamento e correlatas os resultados dos ensaios de introdução de espécies e procedências de eucaliptos. A topografia é plana. A copa dos eucaliptos atinge 25 metros de altura. A densidade do sub-bosque diminui no sentido borda-interior e, dos quatro locais de trabalho, é o de menor densidade. As espécies mais comuns aí são Xylopia brasiliensis, Miconia pepericarpa, Maprounea guianensis e Miconia hispida (Aubert e Oliveira Filho, 1994). Este local não possui fonte de água no seu interior.

\section{Trabalho de campo e cálculos}

O trabalho foi realizado no período compreendido entre abril e novembro de 1995. Foram feitas visitas mensais aos locais de coleta de dados (Matinha, Mata da Subestação, Mata da Capela e Eucaliptal). O horário de visitas foi de 6 h30 às 9:00 horas.

Em cada local de trabalho, o autor marcou uma trilha de cerca de $300 \mathrm{~m}$ de extensão. Essas trilhas eram percorridas numa velocidade previamente calibrada e durante o percurso eram registradas em uma caderneta de campo todas as aves que se manifestassem visual ou auditivamente na trilha e suas proximidades, tomando o cuidado de não registrar o mesmo indivíduo mais de uma vez no dia do levantamento.

Durante o levantamento, observaram-se também os padrões ecológicos de cada espécie, tais como: alimentação, estrato da mata ocupado e preferências por determinados tipos de ambiente dentro da mata.

Foram calculados parâmetros de abundância para cada local de levantamento:

\section{a) Freqüência de ocorrência (FO):}

A freqüência de ocorrência corresponde ao número de dias em que determinada espécie foi observada em relação ao número total de dias de observação:

$$
\mathrm{FO}=\frac{\mathrm{No} * 100}{\mathrm{Nt}}
$$

No = número de dias em que a espécie foi observada $\mathrm{Nt}=$ número total de dias de observação

\section{b) Índice de densidade (ID):}

O índice de densidade corresponde ao número de indivíduos de cada espécie registrado em relação a 100 horas de observação:

$$
\mathrm{ID}=\frac{\mathrm{n} * 100}{\mathrm{Ho}}
$$

$\mathrm{n}=$ número de indivíduos de cada espécie

Ho = número de horas de observação

Também foi calculada uma medida de similaridade entre as áreas, que foi o índice de similaridade de Jaccard (IJ):

$$
\mathrm{IJ}=\frac{\mathrm{c}}{\mathrm{a}+\mathrm{b}+\mathrm{c}} * 100
$$

$\mathrm{c}=$ número de espécies em comum das duas comunidades comparadas

a e $\mathrm{b}=$ número de espécies exclusivas de cada uma das duas comunidades comparadas

Também foi calculado o índice de diversidade de Shannon-Wiener (H'), segundo Magurran (1988), para cada comunidade. Para a obtenção deste, é importante não só o número de espécies na área, mas também a sua densidade populacional.

$$
\mathrm{H}^{\prime}=-\Sigma \text { Piln }(\mathrm{Pi})
$$

$\mathrm{Pi}=$ proporção dos indivíduos da espécie i em relação ao número total de indivíduos da comunidade

\section{Agrupamento das espécies em guildas}

Baseando-se nos dados coletados sobre os padrões ecológicos das espécies nos quatro locais de levantamento quantitativo e em Willis (1979), os autores agruparam as espécies em 13 guildas: 1. Frugívoros; 2. Onívoros do dossel; 3. Onívoros de borda; 4. Onívoros do sub-bosque; 5. Insetívoros do sub-bosque que procuram a presa na folhagem; 6. Insetívoros do sub-bosque que procuram a presa no piso; 7. Insetívoros de borda; 8 . Insetívoros de estrato médio; 9. Insetívoros do dossel; 10. Insetívoros das cascas das árvores; 11. Nectívoros; 12. Granívoros e 13. Carnívoros

No mesmo período deste levantamento quantitativo também foi feito um levantamento qualitativo na Reserva Florestal do Poço Bonito para ser 
comparado em termos de presença-ausência de espécies com os resultados obtidos no campus.

\section{RESULTADOS E DISCUSSÃO}

Nos quatro locais de levantamento quantitativo foram registradas 107 espécies de aves.

O Local 1 apresentou 76 espécies de aves e 791 indivíduos (Tabela 1), tendo um índice de densidade igual a 39,55 indivíduos observados por hora. Mesmo apresentando o maior número de indivíduos contatados entre os quatro locais de estudo, este local não apresenta o maior índice de diversidade $\left(\mathrm{H}^{\prime}=3,55\right)$, ficando com o valor acima somente do Eucaliptal.

Analisando o número de contatos por espécie, observa-se que apenas cinco espécies (Aratinga leucophthalmus, Dacnis cayana, Thraupis sayaca, Tangara cayana, Basileuterus hypoleucus), representam $42,3 \%$ do total de indivíduos contatados e
40,78\% das espécies registradas tiveram entre um e três indivíduos contatados. Estes fatos podem explicar por que este local teve um índice de diversidade mais baixo do que os Locais 2 e 3 . As cinco espécies citadas acima apresentaram os maiores índices de densidade e freqüência relativa. Outras espécies que tiveram índices de densidade e freqüência relativa altos foram Hemithraupis ruficapilla, Pitangus sulphuratus, Turdus leucomelas e Herpsilochmus atricapillus, todos com mais de 20 contatos. Apesar de Aratinga leucophthamus estar entre as espécies com os maiores índices de densidade e freqüência relativa, esta espécie teve um valor baixo de frequiência de ocorrência. Isto se deve ao fato de ela ter sido registrada na área apenas nos meses de setembro e outubro, época em que a pindaíba (Xylopia brasiliensis) frutifica, atraindo para a área um grande número de indivíduos da espécie. As medidas de abundância para este local são apresentadas na Tabela 1.

TABELA 1

Espécies de aves registradas e seus índices de abundância.

\begin{tabular}{|c|c|c|c|c|c|c|c|c|}
\hline & \multicolumn{2}{|c|}{ Local 1} & \multicolumn{2}{|c|}{ Local2 } & \multicolumn{2}{|c|}{ Local 3} & \multicolumn{2}{|c|}{ Local 4} \\
\hline & Fo & ID & Fo & ID & Fo & ID & Fo & ID \\
\hline \multicolumn{9}{|l|}{ Frugívoros } \\
\hline Aratinga aurea & 25 & 20 & 0 & 0 & 0 & 0 & 0 & 0 \\
\hline Aratinga auricapilla & 0 & 0 & 0 & 0 & 25 & 40 & 0 & 0 \\
\hline Aratinga leucophthalmus & 25 & 295 & 0 & 0 & 0 & 0 & 0 & 0 \\
\hline Brotogeris chiriri & 12 & 15 & 0 & 0 & 13 & 10 & 0 & 0 \\
\hline Forpus xanthopterygius & 0 & 0 & 38 & 55 & 0 & 0 & 0 & 0 \\
\hline Penelope superciliaris & 0 & 0 & 13 & 15 & 0 & 0 & 0 & 0 \\
\hline Ramphastos toco & 0 & 0 & 13 & 10 & 0 & 0 & 0 & 0 \\
\hline \multicolumn{9}{|l|}{ Onívoros de Dossel } \\
\hline Conirostrum speciosum & 50 & 55 & 88 & 100 & 100 & 165 & 25 & 20 \\
\hline Dacnis cayana & 87 & 220 & 88 & 115 & 63 & 90 & 38 & 25 \\
\hline Euphonia chlorotica & 25 & 15 & 13 & 5 & 75 & 80 & 13 & 5 \\
\hline Hemithraupis ruficapilla & 87 & 120 & 88 & 135 & 88 & 145 & 25 & 15 \\
\hline Nemosia pileata & 50 & 45 & 25 & 25 & 63 & 75 & 0 & 0 \\
\hline Pipraeidea melanonota & 0 & 0 & 0 & 0 & 13 & 10 & 0 & 0 \\
\hline Vireo olivaceus & 50 & 35 & 13 & 5 & 0 & 0 & 0 & 0 \\
\hline \multicolumn{9}{|l|}{ Onívoros de Borda } \\
\hline Coereba flaveola & 50 & 20 & 38 & 35 & 88 & 50 & 0 & 0 \\
\hline Cyanocorax cristatellus & 0 & 0 & 0 & 0 & 25 & 25 & 13 & 15 \\
\hline Elaenia flavogaster & 75 & 30 & 63 & 40 & 13 & 5 & 0 & 0 \\
\hline
\end{tabular}


TABELA 1 (continuação)

\begin{tabular}{ccccccccc}
\hline Local 1 & \multicolumn{2}{c}{ Local2 } & \multicolumn{2}{c}{ Local 3 } & \multicolumn{2}{c}{ Local 4} \\
Fo & ID & Fo & ID & Fo & ID & Fo & ID \\
\hline
\end{tabular}

Onívoros de Borda (cont.)

Elaenia obscura

Empidonomus varius

Megarynchus pitangua

Myiodynastes maculatus

Myiozetetes similis

Pitangus sulphuratus

Psarocolius decumanus

Saltator similis

Tachyphonus coronatus

Tangara cayana

Tersina viridis

Thraupis palmarum

Thraupis sayaca

Turdus amaurochalinus

Turdus leucomelas

Turdus rufiventris

\section{Onívoros do Sub-bosque}

Chiroxiphia caudata

Trichothraupis melanops

Turdus subalaris

$\begin{array}{cccccccc}13 & 5 & 13 & 5 & 0 & 0 & 0 & 0 \\ 38 & 20 & 25 & 15 & 0 & 0 & 0 & 0 \\ 63 & 45 & 63 & 40 & 13 & 5 & 13 & 5 \\ 25 & 20 & 25 & 15 & 38 & 25 & 0 & 0 \\ 88 & 80 & 50 & 55 & 38 & 30 & 0 & 0 \\ 100 & 125 & 75 & 60 & 70 & 65 & 0 & 0 \\ 0 & 0 & 13 & 10 & 0 & 0 & 0 & 0 \\ 100 & 80 & 75 & 65 & 63 & 60 & 13 & 10 \\ 50 & 45 & 50 & 40 & 25 & 25 & 25 & 10 \\ 100 & 620 & 100 & 275 & 100 & 295 & 88 & 215 \\ 63 & 95 & 13 & 10 & 13 & 40 & 0 & 0 \\ 38 & 20 & 0 & 0 & 0 & 0 & 0 & 0 \\ 88 & 300 & 100 & 265 & 100 & 320 & 63 & 75 \\ 68 & 85 & 38 & 45 & 0 & 0 & 0 & 0 \\ 88 & 105 & 75 & 55 & 50 & 20 & 13 & 5 \\ 13 & 10 & 13 & 5 & 0 & 0 & 0 & 0\end{array}$

Insetívoros do Sub-bosque que procuram a presa na folhagem

Automolus leucophthalmus

Automolus rectirostris

Baryphthengus ruficapillus

Basileuterus hypoleucus

Dysithamnus mentalis

Galbula ruficauda

Lathrotriccus euleri

Malacoptila striata

Platyrinchus mystaceus

Synallaxis cinerascens

Synallaxis ruficapilla

Syndactyla rufosuperciliata

Thamnophilus caerulescens

Todirostrum poliocephalum

$\begin{array}{lccccccc}13 & 15 & 50 & 20 & 0 & 0 & 0 & 0 \\ 38 & 25 & 0 & 0 & 0 & 0 & 0 & 0 \\ 13 & 15 & 0 & 0 & 0 & 0 & 0 & 0\end{array}$

Insetívoros do Sub-bosque que procuram a presa no piso

\begin{tabular}{lcccccccc} 
Aramides saracura & 13 & 10 & 0 & 0 & 0 & 0 & 0 & 0 \\
Basileuterus flaveolus & 13 & 5 & 25 & 15 & 0 & 0 & 13 & 5 \\
Basileuterus leucoblepharus & 100 & 65 & 100 & 110 & 63 & 30 & 0 & 0 \\
\hline
\end{tabular}


TABELA 1 (continuação)

\begin{tabular}{ccccccccc}
\hline Local 1 & \multicolumn{2}{c}{ Local2 } & \multicolumn{2}{c}{ Local 3 } & \multicolumn{2}{c}{ Local 4} \\
Fo & ID & Fo & ID & Fo & ID & Fo & ID
\end{tabular}

Insetívoros do Sub-bosque que procuram a presa no piso (cont.)

Conopophaga lineata

Lochmias nematura

Pyriglena leucoptera

Sclerurus scansor

\section{Insetívoros de Borda}

Camptostoma obsoletum

Hemitriccus nidipendulus

Hylophilus poicilotis

Myiarchus ferox

Myiarchus swainsoni

Myiarchus tyrannulus

Myiophobus fasciatus

Pachyramphus viridis

Synallaxis frontalis

Synallaxis spixii

Tapera naevia

Troglodytes aedon

Tyrannus albogularis

Tyrannus melancholicus

\section{Insetívoros do Estrato Médio}

Contopus cinereus

Herpsilochmus atricapillus

Leptopogon amaurocephalus

Pachyramphus polychopterus

Philydor rufus

Piaya cayana

Tolmomyias sulphurescens

Insetívoros de Dossel

Colonia colonus

Cyclarhis gujanensis

Pachyramphus validus

Parula pitiayumi

\section{Insetívoros de Troncos e Ramos}

\begin{tabular}{lcccccccc} 
Campephilus melanoleucus & 0 & 0 & 13 & 10 & 0 & 0 & 0 & 0 \\
Celeus flavescens & 38 & 20 & 13 & 5 & 0 & 0 & 0 & 0 \\
Colaptes melanochloros & 0 & 0 & 0 & 0 & 12 & 5 & 0 & 0 \\
Lepidocolaptes angustirostris & 25 & 15 & 0 & 0 & 0 & 0 & 13 & 5 \\
Lepidocolaptes squamatus & 13 & 5 & 0 & 0 & 0 & 0 & 0 & 0 \\
\hline
\end{tabular}


TABELA 1 (continuação)

\begin{tabular}{|c|c|c|c|c|c|c|c|c|}
\hline & & & & & & & & \\
\hline & Fo & ID & Fo & ID & Fo & ID & Fo & ID \\
\hline \multicolumn{9}{|c|}{ Insetívoros de Troncos e Ramos (cont.) } \\
\hline Picumnus cirratus & 75 & 85 & 88 & 70 & 100 & 55 & 0 & 0 \\
\hline Veniliornis maculifrons & 13 & 10 & 0 & 0 & 0 & 0 & 0 & 0 \\
\hline Veniliornis passerinus & 25 & 10 & 13 & 5 & 0 & 0 & 0 & 0 \\
\hline Xenops rutilans & 13 & 5 & 13 & 10 & 25 & 15 & 0 & 0 \\
\hline \multicolumn{9}{|l|}{ Nectívoros } \\
\hline Amazilia versicolor & 13 & 5 & 0 & 0 & 13 & 5 & 0 & 0 \\
\hline Amazilia lactea & 38 & 40 & 25 & 80 & 38 & 25 & 0 & 0 \\
\hline Chlorostilbon aureoventris & 0 & 0 & 0 & 0 & 13 & 5 & 0 & 0 \\
\hline Eupetomena macroura & 0 & 0 & 0 & 0 & 13 & 5 & 0 & 0 \\
\hline Phaethornis pretrei & 13 & 5 & 50 & 10 & 38 & 15 & 0 & 0 \\
\hline \multicolumn{9}{|l|}{ Granívoros } \\
\hline Arremon flavirostris & 0 & 0 & 13 & 5 & 63 & 45 & 0 & 0 \\
\hline Columba cayennensis & 25 & 10 & 13 & 5 & 100 & 90 & 0 & 0 \\
\hline Columba picazuro & 38 & 30 & 0 & 0 & 0 & 0 & 13 & 15 \\
\hline Columbina talpacoti & 0 & 0 & 13 & 5 & 100 & 105 & 0 & 0 \\
\hline Coryphospingus pileatus & 0 & 0 & 13 & 5 & 38 & 30 & 13 & 5 \\
\hline Leptotila rufaxilla & 0 & 0 & 38 & 15 & 13 & 10 & 0 & 0 \\
\hline Leptotila verreauxi & 13 & 10 & 13 & 5 & 0 & 0 & 0 & 0 \\
\hline Sporophila nigricollis & 0 & 0 & 13 & 10 & 38 & 15 & 0 & 0 \\
\hline Zonotrichia capensis & 13 & 5 & 0 & 0 & 0 & 0 & 70 & 55 \\
\hline \multicolumn{9}{|l|}{ Carnívoros } \\
\hline Milvago chimachima & 13 & 5 & 0 & 0 & 0 & 0 & 0 & 0 \\
\hline Rupornis magnirostris & 13 & 15 & 0 & 0 & 25 & 10 & 0 & 0 \\
\hline
\end{tabular}

O Local 2 apresentou um número de espécies e indivíduos de 75 e 708, respectivamente, tendo um índice de densidade igual a 35,40 indivíduos observados por hora. Juntamente com o Local 3, este foi o que apresentou o maior índice de diversidade entre os quatro locais estudados $\left(\mathrm{H}^{\prime}=3,73\right)$.

O Local 3 apresentou 68 espécies e 645 indivíduos contatados. Foi o que apresentou, junto com o Local 2, os maiores índices de diversidade $\left(\mathrm{H}^{\prime}=\right.$ 3,70 ) e um índice de densidade de 32,25 indivíduos observados por hora.

Um fator que provavelmente contribuiu para que este local apresentasse junto com o Local 2 os maiores valores de diversidade pode ter sido o fato de que $51,47 \%$ das espécies registradas tiveram um valor intermediário de contatos entre 5 e 20 indivíduos.

Dos quatro locais de levantamento quantitativo, o Local 4 foi o que apresentou o menor número de espécies e indivíduos contatados, 24 e 109, respectivamente, e um índice de densidade de apenas 5,45 indivíduos observados por hora. $\mathrm{O}$ índice de diversidade também foi o menor entre os quatro locais $\left(\mathrm{H}^{\prime}=2,26\right)$.

Uma proporção de $62,5 \%$ das espécies só foi contatada em um único dia de levantamento e as três espécies citadas acima são responsáveis por $62,38 \%$ dos contatos realizados. Estes dois fatos podem conjuntamente explicar o baixo valor de diversidade encontrado neste local. 
Segundo Vielliard \& Silva (1989), uma diversidade entre 1,00 e 2,00 caracteriza a avifauna de florestas temperadas e valores em torno de 3,00 foram obtidos em diversos ambientes tropicais. Neste contexto, os valores de diversidade obtidos nos Locais 1,2 e 3 podem ser considerados altos, apesar do tamanho reduzido de suas fisionomias florestais, enquanto o valor obtido para o Local 4 é considerado baixo.

Apesar do tamanho reduzido dos Locais 1, 2 e 3, os índices de riqueza e diversidade obtidos para os mesmos são considerados altos. Outros autores, como Almeida \& Dias (1996), também encontraram valores altos de riqueza e diversidade em fragmentos pequenos de mata. Segundo Lynch \& Whigham (1984), a diversidade e a densidade da avifauna também podem sofrer aumentos significativos em áreas menores devido ao influxo de espécies generalistas.

Os índices de similaridade avifaunística obtidos entre os quatro locais de levantamento quantitativo são apresentados na Tabela 2. Os locais que apresentam as avifaunas mais similares entre si foram o Local 1 (Matinha) com o Local 2 (Subestação), com 58,95\% de similaridade, e o Local 2 (Subestação) com o Local 3 (Vegetação secundária), com $55,43 \%$ de similaridade. A maior similaridade avifaunística entre os Locais 1 e 2 pode se dever à maior semelhança estrutural da vegetação de ambos, pois são os de maior densidade e complexidade estutural de vegetação.

A obtenção de um índice de similaridade maior entre os Locais 2 e 3 do que entre os Locais 1 e 3 pode ser explicada pelo fato de o primeiro par ter um nível acentuado de perturbação em comparação com Local 1, que é bem menos perturbado e mais protegido. As similaridades obtidas entre o Local 4 (Eucaliptal) e os outros três locais de le- vantamento quantitativo foram baixas. Isto se deve ao fato de a estrutura mais simplificada da vegetação do Eucaliptal, em comparação com os demais, oferecer bem menos recursos para a avifauna.

TABELA 2

Índices de similaridade de Jaccard obtidos entre os quatro locais de levantamento quantitativo.

\begin{tabular}{lcccc}
\hline & Local 1 & Local 2 & Local 3 & Local 4 \\
\hline Local 1 & & 58,95 & 48,45 & 26,58 \\
Local 2 & & & 55,43 & 22,22 \\
Local 3 & & & 24,32 \\
Local 4 & & & \\
\hline
\end{tabular}

Levando-se em consideração o número de espécies (Tabela 3), nota-se que a estrutura trófica não varia muito de um local de levantamento para o outro, com exceção do Eucaliptal, onde faltam frugívoros, nectívoros e carnívoros, e do Local 2 (subestação), onde faltam os carnívoros. Nos locais 1,2 e 3, ocorre uma predominância dos insetívoros seguidos pelos onívoros, fato este já constatado por outros autores (Almeida, 1982c; Motta Júnior, 1990; Krügel \& Anjos, 1996) em fisionomias florestais de pequeno tamanho. Por outro lado, levar em consideração o número de indivíduos contatados em cada nível trófico parece dar uma representação mais real do uso dos recursos alimentares (Motta Júnior, 1990).

Neste contexto, há uma predominância de onívoros no Local 1 (Matinha), no Local 3 (Vegetação secundária) e no Local 4 (Eucaliptal). Segundo Willis (1976), um aumento em onívoros é esperado em fragmentos pequenos, pois a onivoria teria um efeito tampão contra flutuações no suprimento de

TABELA 3

Estrutura trófica dos quatro locais de levantamento quantitativo.

\begin{tabular}{|c|c|c|c|c|c|c|c|c|}
\hline \multirow[b]{2}{*}{ Dieta } & \multicolumn{2}{|c|}{ Local 1} & \multicolumn{2}{|c|}{ Local 2} & \multicolumn{2}{|c|}{ Local 3} & \multicolumn{2}{|c|}{ Local 4} \\
\hline & $\begin{array}{l}\text { № de } \\
\text { Espécie }\end{array}$ & $\begin{array}{c}\text { № de } \\
\text { Indivíduo }\end{array}$ & $\begin{array}{l}\text { № de } \\
\text { Espécie }\end{array}$ & $\begin{array}{c}\text { № de } \\
\text { Indivíduo }\end{array}$ & $\begin{array}{c}\text { № de } \\
\text { Espécie }\end{array}$ & $\begin{array}{c}\text { № de } \\
\text { Indivíduo }\end{array}$ & $\begin{array}{l}\text { № de } \\
\text { Espécie }\end{array}$ & $\begin{array}{c}\text { № de } \\
\text { Indivíduo }\end{array}$ \\
\hline Insetívoros & $38(50 \%)$ & $250(31,60 \%)$ & $39(52 \%)$ & $376(53,10 \%)$ & $35(51,47 \%)$ & $257(39,84 \%)$ & $10(41,6 \%)$ & $15(13,76 \%)$ \\
\hline Onívoros & $26(34,21 \%)$ & $450(56,89 \%)$ & $24(32 \%)$ & $288(40,68 \%)$ & $19(27,94 \%)$ & $306(47,44 \%)$ & $11(45,84 \%)$ & $79(72,47 \%)$ \\
\hline Frugívoros & $3(3,94 \%)$ & $66(8,34 \%)$ & $3(4 \%)$ & $16(2,26 \%)$ & $2(2,94 \%)$ & $10(1,55 \%)$ & & \\
\hline Granívoros & $4(5,26 \%)$ & $11(1,39 \%)$ & $7(9,33 \%)$ & $10(1,41 \%)$ & $6(8,82 \%)$ & $52(9,15 \%)$ & $3(12,50 \%)$ & $15(13,76 \%)$ \\
\hline Nectívoros & $3(3,94 \%)$ & $10(1,26 \%)$ & $2(2,66 \%)$ & $18(2,54 \%)$ & $5(7,35 \%)$ & $11(1,71 \%)$ & & \\
\hline Carnívoros & $2(2,63 \%)$ & $4(0,50 \%)$ & & & $1(1,4 \%)$ & $2(0,31 \%)$ & & \\
\hline
\end{tabular}


alimentos nestes pequenos fragmentos. Por outro lado, o próprio Willis (1979) encontrou evidências que sugerem um aumento no sentido da insetivoria em fragmentos pequenos. No entanto, as fisionomias florestais que ocorrem no campus da UFLA são cerca de um terço menores do que o menor fragmento do trabalho de Willis e devem ter bem menos recursos alimentares para as aves, favorecendo assim a predominância dos onívoros em termos de número de indivíduos.

Matas ciliares são habitats que não sofrem tanta flutuação na disponibilidade de recursos para as aves em relação a ambientes mais secos (Cavalcanti, 1992; Lins \& Fonseca, 1996). Este fator pode explicar por que os Locais 1, 3 e 4 tiveram uma predominância de onívoros em relação aos insetívoros em comparação com o Local 2, que é margeado por um pequeno córrego com uma mata ciliar bem preservada e foi o único local onde os insetívoros predominaram sobre os onívoros em termos de indivíduos. Motta Júnior (1990) também encontrou uma predominância de insetívoros sobre os onívoros num pequeno fragmento de mata ciliar.

No Eucaliptal, há uma grande predominância de onívoros de borda e dossel que parecem usar o ambiente como extensão de sua área de forrageamento. Estes onívoros têm uma maior capacidade para atravessar de um local de levantamento para o outro. Embora os nectívoros, muitos frugívoros e alguns grupos de insetívoros possuam também esta habilidade, eles necessitam de sítios específicos de forrageamento (por exemplo, Philydor rufus e Syndactyla rufosuperciliata, que são insetívoros, necessitam de vegetação densa; bem como frugívoros e nectívoros, que necessitam de frutificações e florações de determinadas espécies de plantas). Notase no Eucaliptal a ausência total de algumas guildas de aves e de muitas espécies componentes de outras guildas (Tabela 1).

O Eucaliptal, apesar de estar próximo do Local 1 (Matinha) e do "Angical", tem um sub-bosque muito aberto e quase nenhuma estratificação vertical em comparação com os outros locais de levantamento. Isto pode explicar por que os onívoros, que não requerem sítios específicos de forrageamento e atravessam facilmente de um local para o outro, têm uma representatividade de cerca de $70 \%$ do número de indivíduos contatados para o Eucaliptal (Tabela 3), e os insetívoros são igualados em número de indivíduos pelos granívoros, que são espécies de borda de mata e locais abertos, não sendo afetados neste tipo de ambiente como muitas espécies de insetívoros.

Nos quatro locais de levantamento quantitativo no campus, é notada a falta de vários frugívoros, insetívoros mais especializados e predadores do topo de cadeia, fato este já observado por vários autores (Motta Júnior, 1990; Leck, 1979; Sick, 1985; Willis, 1979) em fisionomias florestais de tamanho reduzido. Comparando a avifauna das quatro fisionomias florestais estudadas no campus da UFLA com a avifauna florestal da Reserva Florestal Quedas do Rio Bonito, que possui uma mancha de floresta semidecídua montana de cerca de 72 hectares (Oliveira Filho et al., 1994a), observa-se que, nas fisionomias florestais do campus, não há mais representantes das famílias Tinamidae, Trogonidae, Rhinocryptidae e Cotingidae e faltam muitos representantes de várias famílias, como Formicariidae, Dendrocolaptidae, Pipridae, Psittacidae e Picidae. Estas aves são caracterizadas por uma dieta mais especializada em frutos e/ou insetos. Grandes frugívoros como Trogonidae, Cotingidae e algumas espécies de saíras são aves que dependem de uma grande disponibilidade de frutos ao longo do ano e são capazes de se deslocarem por grandes distâncias à procura de árvores com frutificações abundantes e nutritivas, mas que muitas vezes ocorrem numa baixa densidade no ambiente. Já os Dendrocolaptidae são insetívoros especializados, cada indivíduo ocupando territórios extensos, sendo bastante suscetíveis a perturbações ambientais (Silva, 1992). As quatro fisionomias florestais onde foi feito o levantamento no campus são de tamanho muito reduzido e não possuem mais estas frutificações específicas distribuídas ao longo do ano para atender aos frugívoros nem área suficiente para manter esse insetívoros mais específicos, como várias espécies de Dendrocolaptidae e Picidae. Já a área de Reserva Florestal Quedas do Rio Bonito é bem maior, mas nem por isso de tamanho ideal para a conservação das aves, pois nota-se aí a falta de muitas espécies de aves com dietas mais especializadas e predadores de topo de cadeia (por exemplo, Tinamus solitarius, Amazona vinacea e Ramphastos dicolorus, que são frugívoros, Campephilus robustus e Campyloramphus falcularius, que são insetívoros, e Spizaetus spp., que são predadores de topo) que têm a região dentro de sua área de distribuição (Dunning, 1989). Esta comparação serve de alerta para o fato de que, quanto menores as áreas dos fragmentos florestais remanescentes na região, me- 
nor o número de aves que elas podem abrigar. Baseando-se em Marini (1996) e admitindo a possibilidade de que todas as espécies de aves registradas nas matas do campus e na mata da Reserva Florestal Quedas do Rio Bonito ocorriam em todas as áreas antes da fragmentação das matas da região, o Local 1 (Matinha) apresentou uma perda de 48,29\% e o Local 2 (Mata de Subestação) apresentou uma perda de $48,97 \%$ da avifauna que ainda ocorre na região.

\section{REFERÊNCIAS BIBLIOGRÁFICAS}

ALMEIDA, A. F., 1982, Análise das categorias de nichos tróficos das aves de Matas Ciliares em anhembi, Estado de São Paulo. Silvicultura em São Paulo, São Paulo, (16A) 3(1787-1795).

ALMEIDA, M. E. \& DIAS, M. M , 1996, Riqueza e diversidade da avifauna em fragmentos de Mata Ciliar. In: Congresso Brasileiro de Ornitologia, 5, Resumos..., Campinas: Unicamp, p.38.

ANDRADE, M. A., 1995, Lista de campo das aves no Brasil. Belo Horizonte: Fundação Acangaú, 40p.

AUBERT, E. \& OLIVEIRA FILHO, A. T, 1994, Análise multivariada da estrutura fitossociológica do sub-bosque de plantios experimentais de Eucalyptus spp. e Pinus spp. em Lavras (MG). Revista Árvore, Viçosa, 18(3): 194-214.

BERNDT, R. A., 1992, Influência da estrutura da vegetação sobre a avifauna em uma floresta alterada de Araucaria angustifolia e em reflorestamento em TELEMACO BORDA no Paraná, Piracicaba, 221p. (Dissertação - Mestrado em Ciências Florestais/USP.)

CAVALCANTI, R. B., 1992, The importance of forest edges in the ecology of open country cerrado birds. In: P. A. Furley, J. Proctor \& J. A. Ratter (eds.). Nature and Dynamics of Forest - Savanna Boundaries. Londres: Chapman \& Hall, pp. 513-518.

DUNNING, J. S., 1989, South American birds. Newton Square: Harrowood Books, 351p.

KRÜGEL, M. M. \& ANJOS, L. dos., 1996, Riqueza de aves em remanescentes florestais no município de Maringá, Paraná. In: Congresso Brasileiro de Ornitologia, 5, Resumos... Campinas: Unicamp, p. 51.

LECK, C. F., 1979, Avian extinctions in an isolated tropical wet-forest preserve, Ecuador, The Auk, Anchorage, 96: 343-352.

LINS, L. V. \& FONSECA, G. A. B, 1996, O papel da mata ciliar na estruturação de uma comunidade de aves do cerrado. In: Congresso Brasileiro de Ornitologia, 5, Resumos... Campinas: Unicamp, p. 57.
LYNCH, J. F. \& WHIGAM, D. F., 1984, Effects of forest fragmentation on breeding bird communities in Maryland, U.S.A. Biological Conservation, Essex, 28(2): $287-$ 324.

MAGURRAN, A., 1988, Ecological diversity and its Measurement. Cambridge: University Press, 179p.

MARINI, M. A., 1996, Menos matas, menos pássaros. Ciência Hoje, São Paulo, 20(117): 16-17.

MOTTA JÚNIOR, J. C., 1990, Estrutura trófica e composição das avifaunas de três habitats terrestres na região central do Estado de São Paulo. Ararajuba, 1: 65-71.

NEGRET, A., TAYLOR, T., SOARES, R. C., CAVALCANTI, R. B. \& JOHNSON, C., 1984, Aves da região geopolítica do Distrito Federal. Brasília: Ministério do Interior SEMA., 24p.

OLIVEIRA FILHO, A. T., ALMEIDA, R. J., MELLO, J. M. \& GAVILANES, M. L., 1994a, A estrutura fitossociológica e variáveis ambientais em um trecho de mata ciliar do córrego dos vilas boas. Reserva Biológica do Poço Bonito, Lavras (MG). Revista Brasileira de Botânica, São Paulo, 17(1): 67-85.

SICK, H., 1985, Ornitologia Brasileira: uma introdução. Brasília: Universidade de Brasília, 1-2: 827p.

SILVA, W. R., 1992, As aves da Serra do Japi. In: L. P. Morellato (org.). História Natural da Serra do Japi, Campinas: UNICAMP, pp. 238-263.

VELOSO, H. P., RANGEL FILHO, A. L. R. \& LIMA, J. C. A., 1992, Classificação da vegetação brasileira, adaptada a um sistema universal. Rio de Janeiro: IBGE, 123 p.

VIELLARD, J. M. E. \& SILVA, W. R., 1989, Nova metodologia de levantamento quantitativo da avifauna e primeiros resultados no interior do Estado de São Paulo. Brasília, n.p. (Palestra Proferida no IV Encontro Nacional de Anilhadores de Aves.)

VILELA, E. A. \& RAMALHO, M. A. P. , 1979, Análise das temperaturas e precipitação pluviométricas de Lavras, Minas Gerais. Ciência e Prática, Lavras, 3(1): 71-79.

WILLIS, E. O, 1976, Effects of a cold wave on an Amazonia avifauna in the upper Paraguay Drainage, western Mato Grosso, and suggestions on oscine-suboscine relationships. Acta Amazonia, Manaus, 6: 379-394.

WILLIS, E. O., 1979, The composition of avian communities in remanescent woodlots in southern Brasil. Papéis Avulsos de Zoologia, São Paulo, 31(1): 1-25. 